6. Rivkin, M. S., The Great Outdoors: Restoring Children's Rights to Play Outside, National Association for the Education of Young Children, Washington, DC, 1990.

7. Ballouard, J. M., Brischoux, F. and Bonnet, X., Children prioritize virtual exotic biodiversity over local biodiversity. PLOS ONE, 2011, 6, e23152.

8. Genovart, M., Tavecchia, G., Enseñata, J. J. and Laiolo, P., Holding up a mirror to the society: children recognize exotic species much more than local ones. Biol. Conserv., 2013, 159, 484-489.

9. Lindemann-Matthies, P., 'Loveable' mammals and 'lifeless' plants: how children's interest in common local organisms can be enhanced through observation of nature. Int. J. Sci. Edu., 2005, 27(6), 655-677.

10. Bizerril, M. X. A., Children's Perceptions of Brazilian Cerrado Landscapes and biodiversity. J. Environ. Edu., 2004, 35, 47-58.

11. Barraza, L., Children's drawings about the environment. Environ. Edu. Res., 1999, 5, 49-66.

12. Binoy, V. V., Radhakrishna, S. and Kurup, A., Bridging educational institutions for a citizen science project: a case study from Malappuram District, Kerala, India. In Bridging the Communication Gap in Science and Technology (eds Bagla, P. and Binoy, V. V.), Springer, Singapore, 2017, pp. 269-277.

13. Zhang, W., Goodale, E. and Chen, J., How contact with nature affects children's biophilia, biophobia and conservation attitude in China. Biol. Conserv., 2014, 177, 109-116.

14. Mulder, M. B., Schacht, R., Caro, T., Schacht, J. and Caro, B., Knowledge and attitudes of children of the Rupununi: implications for conservation in Guyana. Biol. Conserv., 2009, 142, 879-887.

15. Pomerantz, G., Environmental education tools for elementary schoolchildren: the use of a popular children's magazine. J. Environ. Edu., 1986, 17(4), 17-22.

16. Eagles, P. F. J. and Muffitt, S., An analysis of children's attitudes toward animals. J. Environ. Edu., 1990, 21(3), 41-44.

17. Padma, T. V., India faces uphill battle on biodiversity. Nature, 2013, 504(7479), 200.

18. Roberts, N. S., Impacts of the National Green Corps Program (Eco-Clubs) on students in India and their participation in environmental education activities. Environ. Edu. Res., 2009, 15, 443-464.

19. Ramadoss, A. and Poyyamoli, G., Biodiversity conservation through environmental education for sustainable development: a case study from Puducherry India. Int. Electr. J. Environ. Edu., 2011, 1(2).

20. Chandrasekar, S., Sundaravadivelan, C. and Selvan, A., Awareness on biodiversity among higher secondary students in Vilathikulam area. Int. J. Phys. Soc. Sci., 2012, 2(9).

21. Kerala Forest Statistics, 2016; http://www.ecostat.kerala.gov.in/ images/pdf/publications/Reports_OtherDepts/forest/forest_statistics_ 2016.pdf (accessed on 24 July 2019).

22. Balakrishnan, P., An education programme and establishment of a citizen scientist network to reduce killing of non-venomous snakes in Malappuram district, Kerala, India. Conserv. Evid., 2010, 7, 9-15

23. Huxham, M., Welsh, A., Berry, A. and Templeton, S. J., Factors influencing primary school children's knowledge of wildlife. Biol. Edu., 2006, 41, 9-12.

24. Prokop, P. and Tunnicliffe, S. D., Disgusting animals: primary school children's attitudes and myths of bats and spiders. Eurasia J. Math., Sci Tech., 2008, 4(2).

25. Díez, J., Meñika, A., Sanz-Azkue, I. and Ortuzar, A., Urban and rural children's knowledge on biodiversity in Bizkaia: tree identification skills and animal and plant listing. Int. J. Hum. Social Sci., 2018, 12, 396-400

26. Bhatia, S., Athreya, V., Grenyer, R. and Macdonald, D. W., Understanding the role of representations of human-leopard conflict in Mumbai through media-content analysis. Conserv. Biol., 2013, 27(3), 588-594.

27. Ghimire, H. R., Phuyal, S. and Shah, K. B. Protected species outside the protected areas: People's attitude, threats and conser- vation of the Yellow Monitor (Varanus flavescens) in the Farwestern Lowlands of Nepal. J. Nat. Conserv., 2014, 22(6), 497-503.

28. Radhakrishna, S., Binoy, V. V. and Kurup, A., The culture of environmental education: insights from a citizen science experiment in India. Curr. Sci., 2014, 107, 176-178.

29. Fuller, R. A., Warren, P. H., Armsworth, P. R., Barbosa, O. and Gaston, K., Garden bird feeding predicts the structure of urban avian assemblages. Divers. Distrib., 2008, 14, 131-137.

30. Ng, J. W., Nielsen, C. and St. Clair, C. S., Landscape and traffic factors influencing deer-vehicle collisions in an urban environment. Hum. Wildl. Confl., 2008, 2, 34-47.

31. Baker, P. J., Bentley, A. J., Ansell, R. J. and Harris, S., Impact of predation by domestic cats Felis catus in an urban area. Mammal Rev., 2005, 35, 302-312.

32. Damerell, P., Howe, C. and Milner-Gulland, E. J., Childorientated environmental education influences adult knowledge and household behaviour. Environ. Res. Lett., 2013, 8(1), 015016.

ACKNOWLEDGEMENT. We thank the principals and teachers of schools which participated in this study for their help and support.

Received 7 February 2020; revised accepted 9 June 2021

doi: $10.18520 / \mathrm{cs} / \mathrm{v} 121 / \mathrm{i} 2 / 313-316$

\section{Energy production and its emission generation impact on the environment}

\section{Guanghui Chang ${ }^{1}$, Du Jianguo ${ }^{1}$, Daniel Adu ${ }^{1,2, *}$, Kofi Baah Boamah ${ }^{3}$, Pu tianfeng ${ }^{1}$ and Ransford Darko ${ }^{4}$}

${ }^{1}$ School of Management Science and Engineering, Jiangsu University, Zhenjiang 212013, China

${ }^{2}$ Faculty of Engineering, Accra Technical University, Barnes Road, Accra, Ghana

${ }^{3}$ Department of Banking and Finance, University of Professional Studies, Accra, Ghana

${ }^{4}$ Department of Agricultural Engineering, University of Cape Coast PMB 233, Ghana

Energy contributes greatly to every aspect of life and other activities, and is the main source of economic development of any country. Globally, the demand for electrical power has increased in recent times, causing a major increase in the price of various fuels. Energy production from various renewable and non-renewable resources is not new. However, its impact on the environment is a major concern. Several power plants from large hydro, wind, thermal and others are being used for energy generation, nevertheless the depletion of the environment is the major global concern. The challenges posed to the environment need to be tackled to protect our environment. This study evaluates the state of energy generation and distribution, and its potential environmental impacts on biodiversity, climate change, aquatic life, land use, emission

*For correspondence. (e-mail: 5103160326@stmail.ujs.edu.cn) 
generation, etc. We also propose some environmental management strategies that can help overcome these challenges.

Keywords: Energy production, environmental pollution, emission generation, management strategies.

PROBLEMS associated with energy generation and distribution are not only limited to global warming, but also air pollution, acid rain, ozone depletion, shrinking of forests, radioactive emission, etc. that are added environmental problems. These issues must be considered in the designing and installation of energy generation plants to achieve sustainable development and protect our environment. Research has shown that if care is not taken to stop environmental degradation, it will have negative impact in the future ${ }^{1}$. According to Erdogdu ${ }^{2}$, emissions from geothermal energy constitute approximately $2.5 \%$ and $5.4 \%$ compared to coal and natural gas plants respectively. Studies have shown that emission of mercury from geothermal plants is between 45 and $900 \mathrm{mg} / \mathrm{kW}$, similar to that from coal-fired power plants. This releases about $57-$ $1938 \mathrm{mg} / \mathrm{kW}$ ammonia into the atmosphere, which has a great impact on the environment ${ }^{3}$. Figure 1 shows the comparison of carbon dioxide and sulphur emissions from geothermal and fossil fuel-fired plants ${ }^{3}$. Figure 2 shows greenhouse gas (GHG) emissions for the major economies in the world (1990-2020).

In Europe, environmental protection and structures to guard ecological development are of paramount importance. For example, the Alps and the German state of Bayern, before the development of small and micro hydropower station, are expected to focus on the ecological and environmental protection and their benefits to the nation. If other countries can adopt this system with proper supervision and management, the continuous development of energy resources will have complete benefits of clean energy supply and improve management efficiency, policy enforcement and effective implementation.

Although several small hydropower stations with several management policies exist, each station belongs to either a specific river or valley. If each management group establishes its power station based on the required policies and procedures, the generation and distribution of power will be devoid of pollution. The UK Department for Transport proposed the establishment of small watershed comprehensive management committee to see to the development of small hydropower and bring them together as a group of small hydropower stations to carry out scientific research and improve the technical level of research on content and distributed energy construction ${ }^{4}$. The large, medium, small and micro hydropower plants in developed countries such as the European Union (EU) are quite mature. Nevertheless, further advancement and development will encounter challenges due to technical, economic and environmental aspects. Figure 3 shows the total electricity generation from fuel source by regions in 2017 and 2018.

According to the World Health Organization, about 212 million people or $71 \%$ of the population in the Sub-Saharan African countries (apart from Mauritius and Seychelles) are affected by household air pollution from indoor smoke, pollution due to small particles, carbon monoxide and nitrogen oxides. About 153,229 people die every year due to indoor air pollution, with approximately $45 \%$ of them being children, including the impact due to coal use in several Sub-Saharan African countries on the environment $^{5,6}$. For example, Botswana and South Africa still rely heavily on coal for power generation, causing potential health effects due to air pollution and also increasing the emission of GHGs. Small hydropower plants (SHPs) in rural communities serve two purposes: (i) to protect the ecology and environment, and thus ecological and environmental benefits and (ii) to reach rural electrification target and the annual power generation. Although it is easy to evaluate the efficiency of annual power generation, the environmental and ecological benefits of SHPs are difficult to evaluate. Therefore, the benefits must be balanced, but the different periods should be considered. According to China's first national water census data released in 2013, the number of hydropower stations and the installed capacity of distribution of less than $500 \mathrm{~kW}$ in the country ${ }^{7}$ is 658 , accounting for $52.5 \%$ of the total power generation. The data show that benefits of small and micro hydroelectric power generation are more, but benefit to the environment is less. Therefore, small hydropower development and environmental and ecological protection should be of national concern ${ }^{7}$.

Wind energy use has currently increased with about $20 \%$ growth in annual installed capacity. For example, USA recorded an installed capacity of $51 \mathrm{GW}$ in 2014 , $67 \mathrm{GW}$ in $2015,54 \mathrm{GW}$ in 2016 and $47 \mathrm{GW}$ in 2017, whereas China recorded $23 \mathrm{GW}$ in 2014 , $30.7 \mathrm{GW}$ in 2015 and $23 \mathrm{GW}$ in 2016. As of 2017, a total capacity of $514 \mathrm{GW}$ was recorded globally with several new turbines installed (Figure 4). According to the World Energy Outlook 2017 reports $^{8}$, additional $1664 \mathrm{GW}$ of wind capacity is expected to be installed by 2040 , which will generate about $4270 \mathrm{TW}$ of power, representing 29.3\% capacity. The sustainable development scenario also projects $2629 \mathrm{GW}$ capacity that will generate $6950 \mathrm{TW}$ of power ${ }^{8}$. In recent times, several countries are operating wind turbines of about $6 \mathrm{MW}$. However, an $8 \mathrm{MW}$ plant having $167 \mathrm{~m}$ rotor diameter was constructed in Denmark in 2017. This indicates that 2017 saw a rise of $23 \%$ compared with 2016, with an average size of $5.9 \mathrm{MW}$ new installed turbines ${ }^{9,10}$.

Geothermal energy is another source of renewable energy that has great potential in countries such as New Zealand, USA, Mexico, Indonesia, the Philippines and Italy. This form of energy is cheaper in both production and supply compared to wind and solar energy. As of 

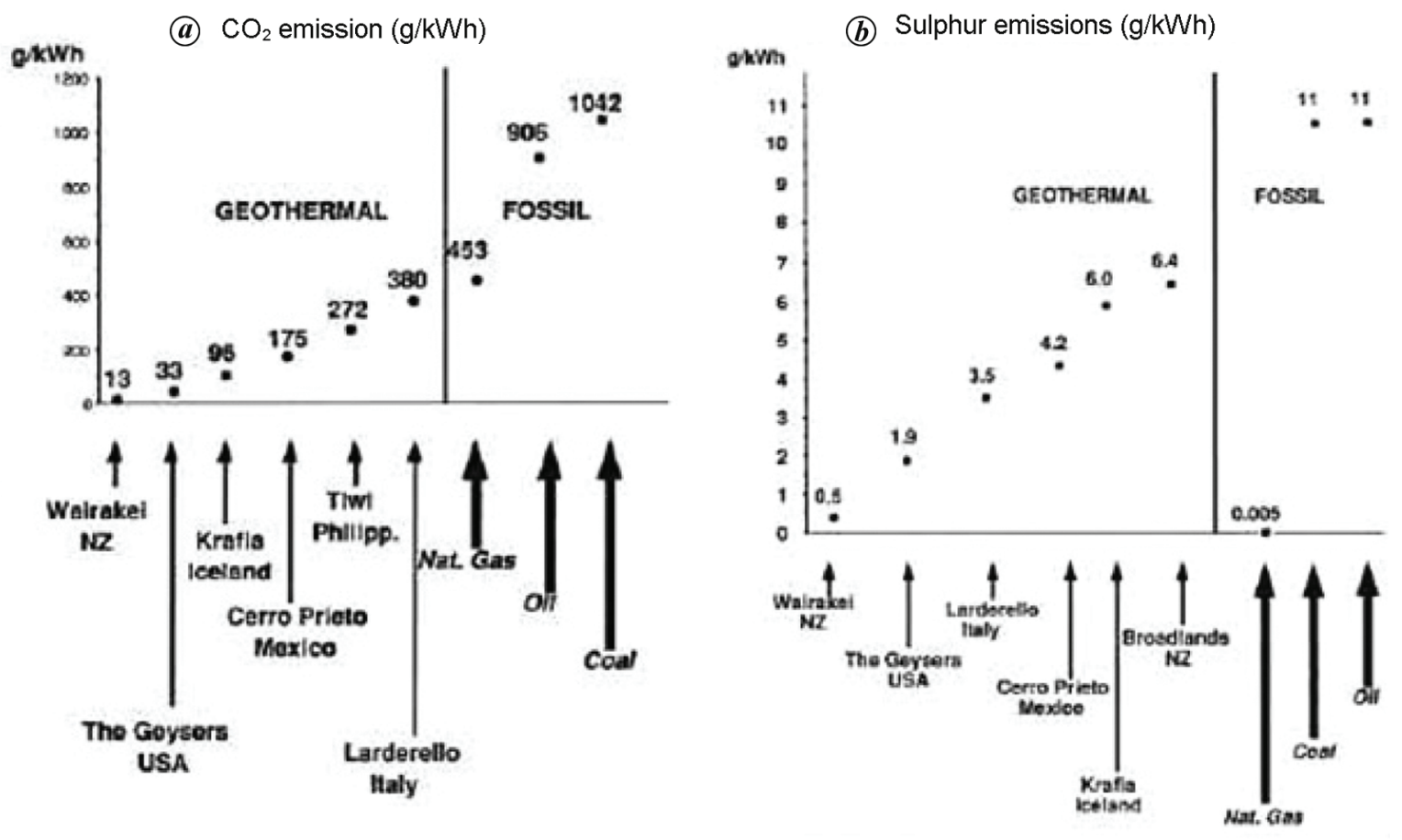

Figure 1. Comparison of (a) $\mathrm{CO}_{2}$ and (b) sulphur emissions from geothermal and fossil fuel-fired plants.

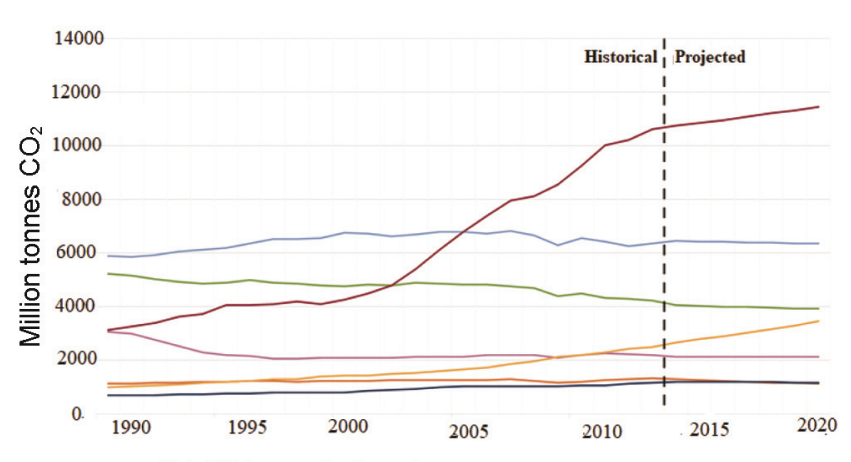

- EU28 — United States — Brazil —Japan —India — China - Russian Federation

Figure 2. Greenhouse gas emissions for the major economies in the world (1990-2020).

2016, 12.7 GW of geothermal energy capacity has been installed worldwide, an increase from $11.85 \mathrm{GW}$ capacity in 2015 (ref. 11). This installed capacity consists of $951 \mathrm{MW}$ from Mexico, $2500 \mathrm{MW}$ from California, 1534 MW from Indonesia, 986 MW from New Zealand, $1916 \mathrm{MW}$ from the Philippines and $824 \mathrm{MW}$ from Italy. However, the 2015 production included Indonesia with $10 \mathrm{TW}$, Italy with $6.2 \mathrm{TW}$, Mexico with $6.5 \mathrm{TW}$, the Philippines with $11 \mathrm{TW}$ and New Zealand with $7.85 \mathrm{TW}$, all from geothermal energy ${ }^{11}$. In Iceland, 5.0 TW constitutes $28.5 \%$ of electricity in the country whereas Japan also generated $533 \mathrm{MW}$ which constitutes $0.25 \%$ of the national energy. In 2016, over 100 geothermal plants of approximately $2.5 \mathrm{GW}$ have been installed in Europe. This added about $15 \mathrm{TW}$ of geothermal energy to the existing capacity. In 2017, Turkey attained an installed capacity of $1100 \mathrm{MW}$. It is projected that geothermal energy installed capacity and generation will triple by 2030. The Global Geothermal Alliance has set a target to increase worldwide geothermal energy capacity to 500 MW by 2030 (ref. 12).

Burning of wood pellets is increasing globally owing to national policies on climate change that have exempted emissions of carbon dioxide from nationwide totals. According to the United Nations, wood pellet production reached 28 million tonnes in 2015 which is an increase of over $40 \%$ in three years, with USA leading as the major source $^{13}$. Electricity generated from waste produced and biomass in 2015 was $429 \mathrm{TW}$ globally from $101 \mathrm{GW}$ capacity ${ }^{14}$ and 314 TW from $86 \mathrm{GW}$ (ref. 15), with biomass having the highest production capacity of about $60 \%$. Nevertheless, biomass energy generation is expected to triple and add $2 \%$ to the global total by 2030 . Figure 5 shows the total primary energy consumption from fuel type by energy sources in 2017 and 2018 . Tables 1 and 2 show the global total electricity generation in 2017 (million tonnes) and global total electricity generation in 2018 (million tonnes) respectively.

Energy production undergoes several stages, with each stage having the ability to affect the environment. Some of these environmental impacts include biodiversity, loss of birds, emissions, consumption of natural resources, depletion of the ozone layer, climate change, etc. These impacts could either be positive or negative. It is therefore necessary to conduct a study to find suitable remedies 

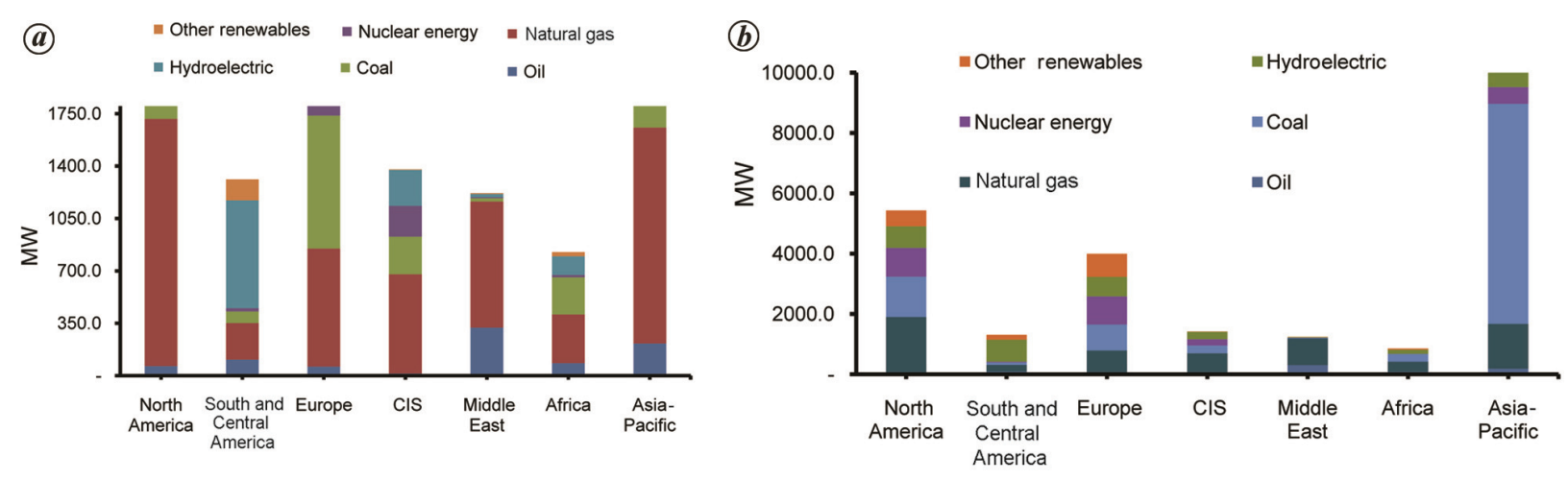

Figure 3. Total electricity generation from source by regions in (a) 2017; (b) 2018 .

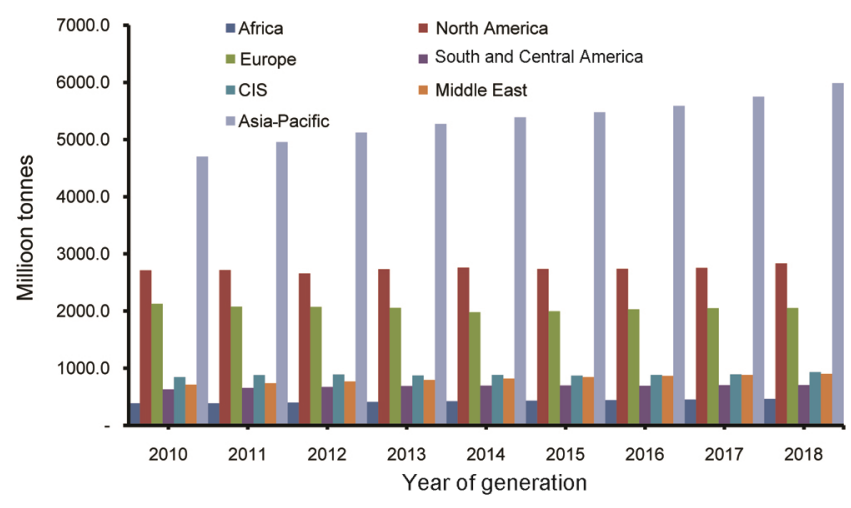

Figure 4. Total primary energy: consumption by regions.

to these impacts. The main impact of electric power generation is change or damage to natural habitats. Changes to ecosystems can also occur as dams convert system of running water into slow water. This disturbs the physicochemical and geobiocentric processes which occur in rivers, and consecutively produce new biotopes with comparatively stable environmental conditions.

Emissions from GHG intensifications of anthropogenic nature are higher compared to the standards set by the Intergovernmental Panel on Climate Change (IPCC). This results in changes to many ecosystems. It is important to maintain a range of temperatures which will make earth habitable, considering the natural greenhouse effect from extreme human activities of GHGs. Currently, measures have been put in place to reduce $\mathrm{CO}_{2}$ and other GHG emissions. They comprise installation of renewable energy services, for example, small hydropower, wind and solar energies, energy efficiency measures, as well as technological expansion of geothermal and ocean energies. Globally, there are several types of hydropower plants. The most common one that is found in many countries is the large hydropower plant, although the small and micro hydropower plants are cheap with no or minimal environmental hazards. Large-scale hydroelectric dams are being constructed in countries like China, Ghana and Brazil. Hydro energy, like other renewables, has an im- pact on the environment which needs to be taken into consideration while constructing hydroelectric dams, particularly large ones.

The amount of land required for constructing a hydro dam or reservoir mostly depends on the size of the project, and the generators as well as turbines to be used. Projects on flat lands usually use more land than the ones constructed on hills or valleys, where deep reservoirs could contain a larger capacity of water in a smaller space. According to Fearnside ${ }^{16}$, the large Balbina hydro plant built on a flat land in Brazil, flooded $2360 \mathrm{~km}^{2}$ at Delaware, whereas it generated only $250 \mathrm{MW}$ of energy. On the contrary, a small $10 \mathrm{MW}$ run-of-the-river plant in a hilly area could use only 2.5 acres of land ${ }^{17}$. Flooding caused by hydro dams and reservoirs has a major impact on the environment as it degrades forests, habitats of flora and fauna, agricultural land, etc. For example, in case of the Three Gorges Dam in China, the whole community had to be moved for constructing the reservoirs ${ }^{18}$. Similar incidents have happened in Ghana for the Bui and Weija dams.

Although several constructed reservoirs are used for other activities, which include irrigation, flood control and recreation, hydropower dams also contribute some major effects on water ecologies. For example, fish and other organisms are mostly affected by turbine impellers which may either kill or injure them. Chemicals released into water bodies may harm them. Noise pollution these also caused by turbines and other generators. With the exception of direct interaction, the effects on wildlife could occur both in the downstream and dammed reservoirs. Water in reservoirs is normally motionless compared to river water. This makes the reservoir contain high amounts of deposits that could develop an excess of algae in addition to other aquatic weeds in it which can cause water pollution and affect wildlife. Thus these weeds sometimes troop other animals in the water bodies as well as plant-life. This can be prevented either by introducing fish that eat these plants or by manual harvesting $^{19}$. Additionally, evaporation in dammed reservoirs also causes loss when compared to flowing rivers. 

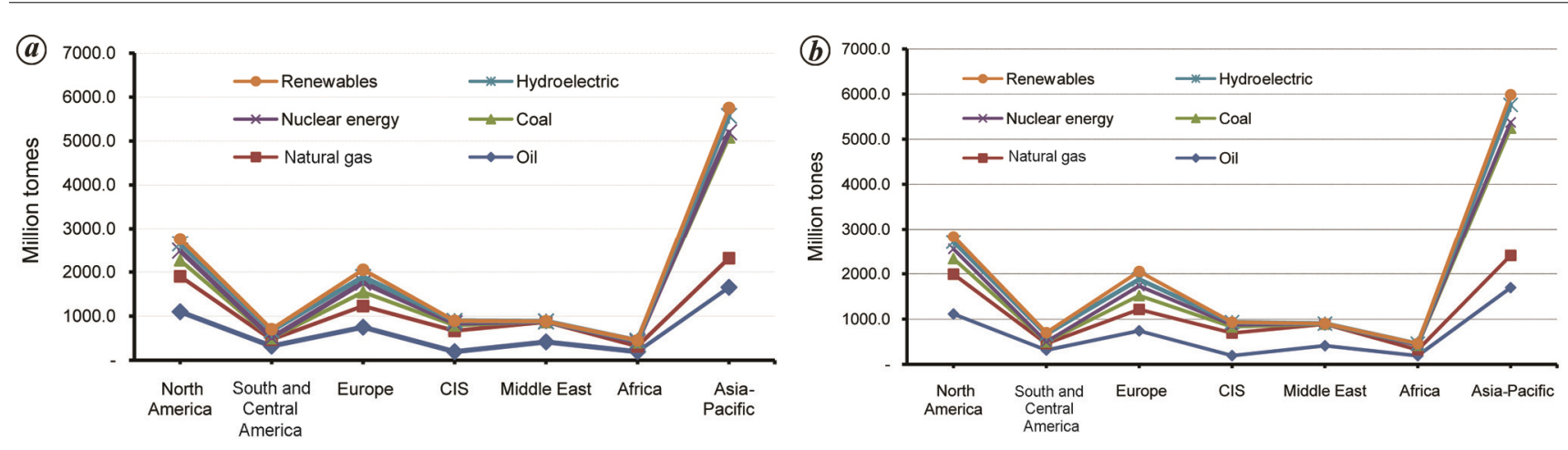

Figure 5. Primary energy: consumption by energy source in (a) 2017; (b) 2018.

Table 1. Global total electricity generation in 2017 (million tonnes)

\begin{tabular}{|c|c|c|c|c|c|c|}
\hline Region/Country & Oil & Natural gas & Coal & Nuclear energy & Hydroelectric & Other renewables \\
\hline Canada & 3.2 & 59.6 & 60.1 & 100.4 & 396.5 & 42.1 \\
\hline Mexico & 38.9 & 196.3 & 30.9 & 10.9 & 31.8 & 19.1 \\
\hline US & 23.0 & 1394.0 & 1310.0 & 847.3 & 296.8 & 417.8 \\
\hline Argentina & 11.6 & 80.8 & 2.0 & 6.1 & 41.5 & 3.0 \\
\hline Brazil & 15.5 & 65.6 & 25.8 & 15.7 & 370.9 & 94.5 \\
\hline Other South and Central American countries & 80.4 & 98.0 & 49.7 & - & 308.0 & 41.9 \\
\hline Germany & 5.6 & 86.7 & 241.9 & 76.3 & 20.2 & 196.2 \\
\hline Italy & 11.5 & 140.3 & 35.1 & - & 34.4 & 67.7 \\
\hline The Netherlands & 1.2 & 57.9 & 31.3 & 3.4 & 0.1 & 17.4 \\
\hline Poland & 2.0 & 10.0 & 133.8 & - & 2.6 & 21.6 \\
\hline Spain & 15.8 & 64.0 & 46.3 & 58.1 & 18.8 & 69.5 \\
\hline Turkey & 1.2 & 110.5 & 97.5 & - & 58.2 & 29.0 \\
\hline Ukraine & 1.4 & 9.1 & 46.7 & 85.6 & 8.7 & 1.9 \\
\hline United Kingdom & 1.6 & 136.8 & 22.5 & 70.3 & 5.9 & 93.4 \\
\hline Other Europe & 21.6 & 172.0 & 233.3 & 642.4 & 436.1 & 220.4 \\
\hline Kazakhstan & 1.9 & 19.8 & 69.9 & - & 11.2 & 0.4 \\
\hline Russian Federation & 10.7 & 515.9 & 168.9 & 203.1 & 185.3 & 1.1 \\
\hline Other CIS & 1.8 & 127.5 & 12.7 & 2.6 & 43.6 & 0.5 \\
\hline Iran & 28.9 & 251.2 & 0.5 & 7.1 & 17.2 & 0.3 \\
\hline Saudi Arabia & 156.9 & 225.1 & - & - & - & 0.1 \\
\hline UAE & 1.6 & 132.4 & - & - & - & 0.5 \\
\hline Other Middle East & 134.8 & 232.3 & 22.3 & - & 3.6 & 4.5 \\
\hline Egypt & 27.7 & 149.4 & - & - & 13.4 & 2.7 \\
\hline South Africa & 0.1 & 1.9 & 221.4 & 15.8 & 0.9 & 10.6 \\
\hline Other Africa & 56.0 & 173.6 & 27.4 & - & 110.3 & 13.6 \\
\hline Australia & 5.3 & 55.2 & 159.1 & - & 13.5 & 25.7 \\
\hline China & 10.7 & 202.8 & 4445.5 & 248.1 & 1165.1 & 492.4 \\
\hline India & 10.1 & 73.5 & 1117.6 & 37.4 & 135.7 & 95.8 \\
\hline Indonesia & 18.9 & 55.7 & 148.0 & - & 18.6 & 13.4 \\
\hline Japan & 65.7 & 401.5 & 361.8 & 29.1 & 79.2 & 98.8 \\
\hline Malaysia & 5.0 & 65.1 & 67.7 & - & 23.1 & 1.3 \\
\hline South Korea & 13.1 & 128.0 & 261.7 & 148.4 & 2.8 & 17.6 \\
\hline Taiwan & 12.8 & 93.4 & 125.9 & 22.4 & 5.4 & 5.3 \\
\hline Thailand & 0.3 & 121.0 & 35.7 & - & 4.7 & 14.9 \\
\hline Vietnam & 0.7 & 44.4 & 76.1 & - & 70.9 & 0.3 \\
\hline Other Asia-Pacific & 72.4 & 201.6 & 116.9 & 8.4 & 130.4 & 31.1 \\
\hline
\end{tabular}

Installation and disassembling of hydropower plants normally causes global warming due to significant emissions. The emissions depend on the size and topography of the land swamped by the reservoir as well as the size of the river. According to IPCC and the National Academy of Sciences, USA, SHPs produce between 0.01 and 0.03 pounds of carbon dioxide equal to $\mathrm{kWh}$. However lifecycle emissions produced by large hydropower plants constructed within the semiarid regions constitute about 0.06 pounds of carbon dioxide equal to $\mathrm{kWh}$. Therefore, global warming due to emissions produced by large hydropower plants in temperate zones is high considering the approximations for lifecycle. Nonetheless, the present estimation indicates that lifecycle emissions could be above 0.5 pounds of 
RESEARCH COMMUNICATIONS

Table 2. Global total electricity generation in 2018 (million tonnes)

\begin{tabular}{|c|c|c|c|c|c|c|}
\hline Region/Country & Oil & Natural gas & Coal & Nuclear energy & Hydroelectric & Other renewables \\
\hline Canada & 3.2 & 58.7 & 59.3 & 100.0 & 387.3 & 45.3 \\
\hline Mexico & 36.8 & 196.7 & 29.2 & 13.6 & 32.4 & 21.4 \\
\hline USA & 26.4 & 1578.5 & 1245.8 & 849.6 & 288.7 & 458.5 \\
\hline Argentina & 6.4 & 85.3 & 2.0 & 6.9 & 41.6 & 3.8 \\
\hline Brazil & 11.5 & 46.8 & 21.9 & 15.6 & 387.7 & 104.5 \\
\hline Germany & 5.2 & 83.0 & 229.0 & 76.1 & 16.9 & 209.2 \\
\hline Italy & 10.9 & 127.2 & 36.6 & - & 45.9 & 66.0 \\
\hline The Netherlands & 0.6 & 57.3 & 30.0 & 3.5 & 0.1 & 18.6 \\
\hline Poland & 1.2 & 12.4 & 134.7 & - & 2.0 & 19.5 \\
\hline Spain & 15.6 & 57.2 & 38.4 & 55.6 & 35.2 & 70.7 \\
\hline Turkey & 0.6 & 92.2 & 111.7 & - & 59.5 & 37.7 \\
\hline Ukraine & 0.5 & 12.1 & 47.7 & 84.4 & 9.9 & 2.6 \\
\hline United Kingdom & 1.7 & 131.5 & 16.8 & 65.1 & 5.5 & 105.6 \\
\hline Kazakhstan & 1.7 & 24.2 & 70.2 & - & 10.3 & 0.7 \\
\hline Russian Federation & 11.4 & 521.5 & 177.5 & 204.5 & 190.2 & 1.3 \\
\hline Iran & 23.0 & 269.1 & 0.5 & 7.0 & 10.8 & 0.4 \\
\hline Saudi Arabia & 150.6 & 233.0 & - & - & - & 0.2 \\
\hline UAE & 1.6 & 134.4 & - & - & - & 1.0 \\
\hline Egypt & 22.1 & 160.9 & - & - & 13.5 & 3.5 \\
\hline South Africa & 0.1 & 1.9 & 225.0 & 11.1 & 0.9 & 12.4 \\
\hline Australia & 5.3 & 50.2 & 156.6 & - & 17.3 & 31.9 \\
\hline China & 10.7 & 223.6 & 4732.4 & 294.4 & 1202.4 & 634.2 \\
\hline India & 10.1 & 74.3 & 1176.3 & 39.1 & 139.7 & 121.5 \\
\hline Indonesia & 20.2 & 59.6 & 156.4 & - & 16.4 & 14.8 \\
\hline Japan & 60.0 & 386.9 & 347.2 & 49.1 & 81.0 & 112.1 \\
\hline Malaysia & 2.3 & 66.4 & 74.1 & - & 24.2 & 1.5 \\
\hline South Korea & 9.1 & 160.4 & 261.3 & 133.5 & 2.9 & 21.9 \\
\hline Taiwan & 8.4 & 94.8 & 126.6 & 27.7 & 4.5 & 6.4 \\
\hline Thailand & 0.2 & 116.3 & 35.8 & - & 7.6 & 17.8 \\
\hline Vietnam & 0.7 & 44.3 & 86.7 & - & 80.7 & 0.5 \\
\hline
\end{tabular}

carbon dioxide which is equal to $\mathrm{kWh}$. This is due to the decomposition of vegetation and soil after flooding which release carbon dioxide and methane ${ }^{20,21}$.

Environmental regulations have caused difficulties for developing SHPs in many countries along with increasing installation costs. There has been advancement in SHP technology to lower its environmental impact and provide suitable protection for the fauna and flora, especially migratory fish. In many developed countries, new environmental protection regulations have prevented the development of SHPs potential sites since the regulations either involve additional costs that make projects unfeasible, or they prevent development entirely. In Norway and Sweden, for instance, feasible SHPs potential has been developed due to the implementation of a new regulation that has rendered development of potential sites illegal or economically unviable. Similarly, the government of Austria has made it mandatory to conserve fish that are in the rivers used by SHPs. Though ensuring a low environmental impact, governments should consider SHP developers as important stakeholders when formulating and implementing regulations. Also, the industry must continue to lower the impact of SHPs and seek lower-cost technology to ensure that environmentally sound sites remain viable. Wind energy like other renewable energy resources has undesirable effects on the environment.
These include noise pollution, visual effect, shadow flicker and reflectance, etc. Wind turbine installations cause visual impact on the environment, leading to accidents particularly along roadsides. Constructing several wind turbines also disturbs the landscape, for instance, visibility to one side. This environmental visual effect could be reduced with suitably modifying the size of the turbine and design during installation. Another effect is the noise produced by wind farms and turbine blades as they rotate. This affects the health and comfort of people living nearby.

Before any project is commenced, it is necessary to conduct environmental impact assessment (EIA), which will help forecast the impact it will have on the environment and recommends whether the project can be carried out or not. This assessment should be impartial devoid of any political influence.

It is also necessary to consider Environmental Management System (EMS) for the protection of the environment in each energy project. EMS is a part of the management system of an organization which is responsible for developing, implementation and management of its environmental policy. This comprises organizational structure responsibilities, operational planning, procedures, processes, practices and resources to develop. Application of this system involves studying the legislation and standards appropriate for all facilities, identifying the 
major environmental impacts, valuation of the risks of these impacts, plans to decrease the risks, as well as all the appropriate prepared management systems. This system allows the organization to evaluate the efficiency of the procedures and technical instructions in the application of environmental policies and objectives.

Government policies that support specific renewables resource generation usually produce clear grants together with other mechanisms for example quota duties, feed-in tariffs and energy tax exemptions. In the EU, feed-in tariffs are popular. The taxes levied on a specific renewable resource are justified by climate change or associated policies. A clear example is found in Sweden, where taxes have been levied on energy resources such as nuclear at around EUR 0.6 cents $/ \mathrm{kWh}$. Others such as environmental taxes can also be implemented to check and control environmental pollution caused by energy generation. In Australia, it is mandatory for energy traders to source identified amounts of power from new renewables, except hydropower. This has brought a contingency tax of AUD $4 \mathrm{c} / \mathrm{kWh}$ for retailers who do not obey the laws. Ten of the 29 states in India are practising feed-in tariffs. For example, Karnataka levies 2.75 times the tariff for coal-produced energy together with a federal incentive scheme paying one-third of the coal-fired tariff. Similarly, in Germany and Portugal, small-scale PV contribution is stimulated by high feed-in tariffs of 48 and $50 \mathrm{c} / \mathrm{kWh}$ respectively.

Energy from renewable sources are clean and suitable to overcome electricity crisis worldwide and improve economic growth with minimal or no environmental hazards. Wind energy has shown about $20 \%$ growth in annual installed capacity. As of 2017 , a total capacity of $514 \mathrm{GW}$ was recorded globally with several new turbines being installed. Environmental protection and measures to protect ecological development are important in Europe. Development of SHPs must focus on ecological and environmental protection and benefits. SHPs generate energy with minimal environmental effects. Wind, geothermal and solar energy sources have minimal emissions compared with fossil fuels, which makes them suitable for application, and to reduce dependence on the imported fuels. However all these energy sources have some impact on the environment that needs to be controlled before production. Several developing countries do not have access to electricity due to the fear of environmental pollution caused by some energy generation sectors. In this study, we have discussed various environmental impacts from energy generation, such as on biodiversity, climate change, wildlife, global warming, etc. EIA, EMS, quota duties, feed-in tariffs and energy tax exemptions are some of the remedies to overcome these challenges.

1. Dincer, İ., Hepbasli, A. and Ozgener, L., Geothermal energy resources. In Encyclopedia of Energy Engineering and Technology (ed. Capehart, B. L.), CRC Press, New York, 2007, pp. 744-752.
2. Erdogdu, E., A snapshot of geothermal energy potential and utilization in Turkey. Renew. Sustain. Energ. Rev., 2009, 13, 2535-2543.

3. Barbier, E., Geothermal energy technology and current status: an overview. Renew. Sustain. Energ. Rev., 2002, 6, 3-65.

4. UK, Carbon and sustainability reporting within the renewable transport fuel obligation. Department for Transport, Government of the United Kingdom, January 2008; https://www.gov.uk/ government/collections/renewable-transport-fuels-obligation-rtfoorders (retrieved on 29 February 2018).

5. WHO, Burden of disease from household air pollution for 2012 . World Health Organization, Geneva, 2014; www.who.int/phe/ health topics/outdoorair/databases

6. Schwaiger, K. and Pfaundler, M., Situation report on hydropower generation in the Alpine region focusing on small hydropower [R/OL]. The Alpine Convention, Evian, France, 2011, 26; http://www.alpconv.org/en/organization/conference/Documents/ AC11_B8_1_Situation_Repor_FIN_annex024_1.pdf?AspxAutoDetectCookieSupport=1 (retrieved on 16 June 2014).

7. Research Institute of Rural Electrification, Ministry of Water Resources, State of the art of small hydropower (EB/OL).

8. World Energy Outlook 2017. http://dx.doi.org/10.1787/weo-2017-en, ISBN: 978-92-64-28230-8.

9. Hughes, G., The performance of wind farms in the United Kingdom and Denmark. Renewable Energy Foundation, 2012.

10. MacKay, D., On the performance of wind farms in the United Kingdom (response to Hughes, The performance of wind farms in the United Kingdom and Denmark). University of Cambridge and Department of Energy and Climate Change, UK, 28 May 2013.

11. REN21 Renewables global status report, 2013.

12. International Energy Agency, Energy technology perspectives, 2016.

13. https://globaltimbertrackingnetwork.Org/tag/wood-identification/ (accessed on 20 July 2020).

14. OECD IEA 2008, 2009, 2010 World Energy Outlook.

15. IRENA, Renewable energy statistics, International Renewable Energy Agency, 2017.

16. Fearnside, P. M., Brazil's Balbina Dam: environment versus the legacy of the Pharaohs in Amazonia. Environ. Manage., 1989, 13(4), 401-423.

17. Tverberg, G., Intermittent renewables can't favourably transform grid electricity, Our Finite World, 31 August 2016.

18. National Renewable Energy Laboratory, NREL. Renewable Electricity Futures Study (eds Hand, M. M. et al.), National Renewable Energy Laboratory, Golden, CO, USA, NREL/TP-6A2052409, 2012, 4 vols.

19. Yardley, J., Chinese dam projects criticized for their human costs. New York Times, 19 November 2007.

20. National Renewable Energy Laboratory, Renewable electricity futures study, 2012.

21. Intergovernmental Panel on Climate Change, IPCC, IPCC Special Report on Renewable Energy Sources and Climate Change Mitigation. Prepared by Working Group III of the Intergovernmental Panel on Climate Change (eds Edenhofer, O. et al.), Cambridge University Press, Cambridge, United Kingdom, 2011, p. 1075.

22. NAS, Electricity from renewable resources: status, prospects, and impediments. National Academy of Sciences, Washington, DC, USA, 2010; http://www.nap.edu/openbook.php?record_id=12619

ACKNOWLEDGEMENTS. We thank Joyce Adu and Dr Adu-Kumi Sam Jnr for reading the manuscript and correcting the language. This work was supported by The National Science Foundation of China with Grant Numbers 71974081, 71704066 and 71971100 and Special Funds of the National Social Science Fund of China (grant number 18VSJ038).

Received 20 April 2021; accepted 3 May 2021

doi: $10.18520 / \mathrm{cs} / \mathrm{v} 121 / \mathrm{i} 2 / 316-322$ 